\title{
Subconjunctival administration of low-dose murine allogeneic mesenchymal stromal cells promotes corneal allograft survival in mice
}

Oliver Treacy ${ }^{1,2+}$, Kevin Lynch ${ }^{1,2+}$, Nick Murphy ${ }^{1+}$, Xizhe Chen ${ }^{1}$, Ellen Donohoe ${ }^{1}$, Aoife Canning ${ }^{1}$, Paul Lohan ${ }^{1}$, Georgina Shaw ${ }^{1}$, Gerry Fahy ${ }^{3}$, Aideen E. Ryan ${ }^{1,2,4}$ and Thomas Ritter ${ }^{1,4^{*}}$ (D)

\begin{abstract}
Background: Systemic administration of mesenchymal stromal cells (MSCs) has been efficacious in many inflammatory disease settings; however, little data are available on the potential immunomodulatory effects following local MSC administration in the context of corneal transplantation. The purpose of this study was to assess the potential of subconjunctival injection of MSCs to promote corneal allograft survival.
\end{abstract}

Methods: MSCs were isolated from female C57BL/6 $\left(\mathrm{H}-2^{\mathrm{k}}\right)$ or Balb/c $\left(\mathrm{H}-2^{d}\right)$ mice and extensively characterized. An allogeneic mouse corneal transplant model was used with Balb/c mice as recipients of C57BL/6 grafts. A dosefinding study starting with $5 \times 10^{5}$ MSCs injected subconjunctivally at day -7 was tested first followed by a more clinically translatable low-dose single or dual injection strategy on day -1 and day +1 before/after transplantation. Graft transparency served as the primary indicator of transplant rejection while neovascularization was also recorded. Lymphocytes (from draining lymph nodes) and splenocytes were isolated from treatment groups on day 2 post-transplantation and characterized by flow cytometry and qRT-PCR.

Results: Both high- and low-dose injection of allogeneic MSCs on day -7 led to $100 \%$ graft survival over the observation period. Moreover, low-dose dual subconjunctival injection of $5 \times 10^{4}$ allogeneic MSCs on day -1 or day +1 led to $100 \%$ allograft survival in transplant recipients $(n=7)$. We also demonstrate that single administration of allogeneic MSCs on either day -1 or day +1 promotes rejection-free graft survival in 100\% $(n=8)$ and $86 \%(n=7)$ of transplanted mice, respectively. Early time point ex vivo analysis suggests modulation of innate immune responses towards anti-inflammatory, pro-repair responses by local MSC administration.

(Continued on next page)

\footnotetext{
*Correspondence: thomas.ritter@nuigalway.ie

${ }^{\dagger}$ Oliver Treacy, Kevin Lynch and Nick Murphy contributed equally to this work.

${ }^{1}$ College of Medicine, Nursing and Health Sciences, Biomedical Sciences, Regenerative Medicine Institute, National University of Ireland Galway, Galway, Ireland

${ }^{4}$ CURAM Centre for Research in Medical Devices, National University of Ireland, Galway, Ireland

Full list of author information is available at the end of the article
}

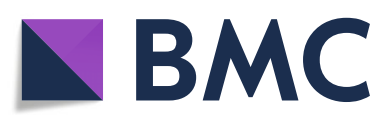

(๑) The Author(s). 2021 Open Access This article is licensed under a Creative Commons Attribution 4.0 International License, which permits use, sharing, adaptation, distribution and reproduction in any medium or format, as long as you give appropriate credit to the original author(s) and the source, provide a link to the Creative Commons licence, and indicate if changes were made. The images or other third party material in this article are included in the article's Creative Commons licence, unless indicated otherwise in a credit line to the material. If material is not included in the article's Creative Commons licence and your intended use is not permitted by statutory regulation or exceeds the permitted use, you will need to obtain permission directly from the copyright holder. To view a copy of this licence, visit http://creativecommons.org/licenses/by/4.0/. The Creative Commons Public Domain Dedication waiver (http://creativecommons.org/publicdomain/zero/1.0/) applies to the data made available in this article, unless otherwise stated in a credit line to the data. 
(Continued from previous page)

Conclusion: This work demonstrates that low-dose subconjunctival injection of allogeneic MSCs successfully promotes corneal allograft survival and may contribute to refining future MSC immunotherapies for prevention of corneal allograft rejection.

Keywords: Corneal transplantation, Mesenchymal stromal cells, Allogeneic, Subconjunctival, Immunomodulation, Macrophage, Graft survival, Mouse

\section{Introduction}

Corneal transplantation is the last option for patients suffering from serious ocular disease or injury [1-3]. Topical corticosteroids with or without adjuvant immunosuppressant therapy remains the gold standard treatment for preventing corneal allograft rejection; however, patients are still highly susceptible to immunemediated rejection. Therefore, novel therapies are urgently needed to improve the prognosis of corneal transplantation.

Mesenchymal stromal cells' (MSCs) therapeutic potential is associated with their ability to effectively modulate host repair responses and inflammation and their safety profile following administration to patients $[4,5]$. We and others have shown that systemic administration of MSCs prolongs corneal allograft survival and promotes ocular surface regeneration [6-10]. Although the mechanisms of MSC-induced immunomodulation in vivo are not completely understood, data suggest that induction/ expansion of regulatory $\mathrm{T}$ cells (Tregs) or myeloidderived suppressor cells in the lung $[7,11]$ play an important role. Most pre-clinical and clinical studies administer MSCs systemically; however, this often requires high doses of cell numbers to achieve a therapeutic effect, which may lead to adverse side effects [12, 13]. In contrast, local application of MSCs may have the potential to exert local immunomodulatory effects, which may allow for the application of reduced cell numbers. Subconjunctival injection of MSCs (albeit large numbers of cells) seems to be beneficial in cornea injury models [14, 15] and in a rat corneal allotransplant model [16]. Here, we show that, following subconjunctival administration, allogeneic donor-derived but not syngeneic MSCs promote corneal allograft survival in a dose-dependent manner. Our data indicate that a single bolus of locally administered MSCs is sufficient to significantly attenuate corneal allograft rejection. Moreover, early time point ex vivo analysis suggests modulation of innate immune responses by local MSC administration.

\section{Materials and methods}

Mouse corneal transplantation

A fully allogeneic major histocompatibility complex (MHC) class I/II disparate cornea transplant model was used for these studies as described previously [10]. See Additional file 1 for details.

\section{Generation and characterization of mouse MSCs}

Isolation of mouse MSCs was performed as described [10], and MSC preparations were extensively characterized for the expression or absence of specific cell surface markers by flow cytometry and for their differentiation capacity (Supplemental Figure 1 and 2) [7, 10, 17, 18].

\section{RAW264.7 macrophage/MSC co-culture assay}

See Additional file 1 for details.

\section{Subconjunctival administration of MSCs}

MSCs were collected, washed three times with DPBS (Thermo-Fisher Scientific, Dublin, Ireland), and filtered through a $40-\mu \mathrm{m}$ filter (Thermo-Fisher Scientific) before administration. Mice were briefly anesthetized using isoflurane and subconjunctivally administered $5 \times 10^{4}$ (low-dose) or $5 \times 10^{5}$ (high-dose) MSCs in $20 \mu \mathrm{l}$ or $50 \mu \mathrm{l}$ of DPBS, respectively, using a 30-G needle.

Generation of single-cell suspensions from lymph nodes and spleens and flow cytometry

Single-cell suspensions of draining lymph nodes (dLNs) and spleens were prepared as detailed in [10]. See Additional file 1 for details.

\section{RNA isolation and RT-PCR}

See Additional file 1 for details.

\section{Statistical analysis}

See Additional file 1 for details.

\section{Results}

Subconjunctival injection of allogeneic MSCs promotes corneal allograft survival in Balb/c mice

MSCs were isolated from $\mathrm{C} 57 \mathrm{BL} / 6$ and Balb/c mice as previously described and extensively characterized [10, 17]. MSCs were shown to conform to ISCT criteria (Supplemental Figure 1 and 2). Data relating to characterization and differentiation of Balb/c MSCs can be found at [10]. 
Next, we investigated if local administration of MSCs could promote mouse corneal allograft survival by applying two different injection strategies with either one or two MSC injections. First, recipient Balb/ c mice received either no injection or a single bolus injection of $5 \times 10^{5}$ (high-dose) or $5 \times 10^{4}$ (low-dose) allogeneic $\mathrm{C} 57 \mathrm{BL} / 6 \mathrm{MSCs}$ in the subconjunctival space followed by allogeneic corneal transplantation 7 days later. Transplant survival was monitored over a period of 40 days by microscopy and graft opacity as the main indicator of cellular infiltration and endothelial dysfunction was recorded. The majority of allogeneic control transplanted mice rejected their corneal transplant before the end of the observation period (mean survival time (MST), 21.3 days \pm 11.0 SD). In contrast, animals that received a bolus of $5 \times$ $10^{5}$ MSCs had a $100 \%$ survival rate (Fig. 1a). Interestingly, low-dose $\left(5 \times 10^{4}\right)$ was equally as efficacious as high-dose treatment (Fig. 1a). Earlier onset of neovascularization was observed in the high-dose allo-MSC group (Fig. 1c), but no significant difference in opacity was seen between mice receiving either low- or high-dose allo-MSCs (Fig. 1b). Representative images of low-dose MSC-treated and allogeneic transplant control mice are shown in Fig. 1d.

Following confirmation that local administration of low-dose MSCs was just as efficacious as high-dose treatment, we modified our injection strategy towards a more clinically feasible injection protocol. We investigated if subconjunctival MSC injection on the day before and/or after the day of transplantation could promote corneal allograft survival. We found that double injection of low-dose MSCs on day -1 and day +1 led to $100 \%$ corneal allograft survival (Fig. 2a). Interestingly, a single injection strategy either on day -1 or day +1 also resulted in significant prolongation of allograft survival (Fig. 2a). While not reaching statistical significance, there was a clear trend towards reduced corneal opacity in all MSC treatment groups versus PBS-treated control mice (PBS $\mathrm{v}$ allo-MSC (D-1, D+1): $p=0.0717$; PBS v allo-MSC (D-1): $p=0.0699$; PBS v allo-MSC (D+1): $p=0.0641$ ) (Fig. 2b). Neovascularization levels were comparable between all groups (Fig. 2c). Interestingly, dual injection of syngeneic, recipient-derived MSCs had no significant impact on corneal allograft survival (Fig. 2a).

\section{Early time point analysis of draining lymph nodes following subconjunctival injection of MSCs indicates innate immune cell modulation}

As it is well known that the draining lymph nodes (dLNs) play an important role in corneal allograft survival and rejection, we investigated the immunological profile of lymph node cells following dual MSC injection on day $-1 /+1$. MSC-treated transplanted animals were sacrificed 2 days posttransplantation, and LN cells were isolated and profiled by flow cytometry and qRT-PCR. Although we found no significant differences in MHC class II and CD80 expression on $\mathrm{CD} 11 \mathrm{~b}+$ and $\mathrm{CD} 11 \mathrm{c}+$ cells (Fig. 3b-e) (see Fig. 3a for gating strategy) between the two groups, we found that the proportion of CD206-expressing CD11b+ cells (indicative of nonclassical, anti-inflammatory M2-like macrophages) was significantly increased in the dLNs of mice treated with two doses of allo-MSCs (Fig. 3f). qRT-PCR analysis of dLNs also showed a trend towards an increase in TGF- $\beta$ mRNA expression (though not statistically significant) in allo-MSC-treated animals (Fig. 3g). Analysis of the same immune cell subsets in the spleen revealed no significant differences between allo-MSC and PBS control treated transplanted mice (Supplemental Figure 3A-E). This would suggest that the observed increased proportion of CD11b+CD206+ cells is a LN-specific finding. To further validate that MSCs (specifically allo-MSCs) can induce a M2-like anti-inflammatory macrophage phenotype, we cocultured RAW264.7 macrophages with either syngeneic $(\mathrm{Balb} / \mathrm{c})$ or allogeneic MSCs (C57BL/6) for $72 \mathrm{~h}$ (see Supplemental Figure 4A for experimental outline). Allo-MSCs were capable of both polarizing M0 macrophages (Supplemental Figure 4B) and skewing M1-polarized macrophages (Supplemental Figure 4C) to a M2-like phenotype, as measured by fold expression of the M2 marker arginase-1 (Arg-1). There was also a clear increase in Arg-1 expression by M2polarized macrophages following co-culture with alloMSCs (Supplemental Figure 4D). Confirmation that Arg-1 expression was coming from the macrophages and not the MSCs themselves was obtained by assessing Arg-1 expression by the MSCs alone. As shown in Supplemental Figure 4E, neither MSC population expressed Arg-1 mRNA at a physiologically relevant level. While not reaching statistical significance, analysis of early $\mathrm{CD} 4+\mathrm{T}$ cell responses showed trends towards increased levels of both CD69+ (early marker of activation) (Fig. 4b) and CD25+ (Fig. 4c) expressing $\mathrm{T}$ cells (see Fig. 4a for gating strategy). This is perhaps reflective of the early time point posttransplantation at which the analysis was performed. CD4+CD25+Foxp3+ Treg levels were comparable between both groups (Fig. 4d). In summary, these data show that local administration of allo-MSCs promotes corneal allograft survival and modulates innate immune cell populations in the dLNs towards a more anti-inflammatory/regulatory phenotype early after MSC injection. 


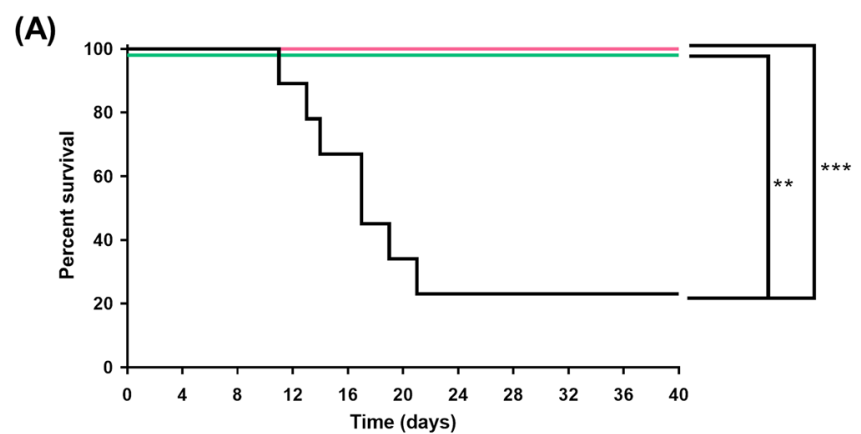

(B)

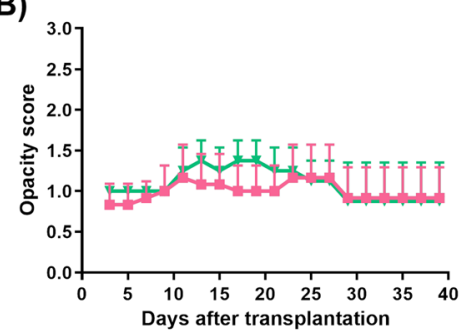

(C)

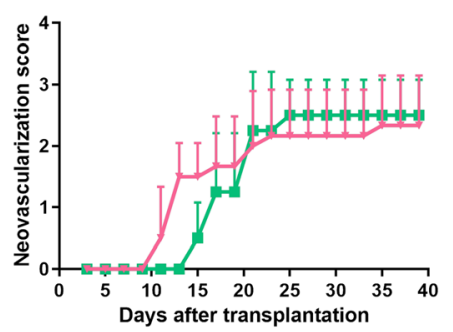

- Allogeneic Transplantation ( $\mathrm{n}=9$ )

- Allogeneic Transplantation $+5 \times 10^{5}$ allo MSC $(n=6)$

- Allogeneic Transplantation $+5 \times 10^{4}$ allo MSC $(n=4)$

(D)

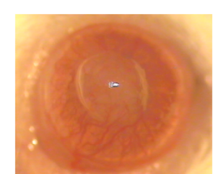

Day 13

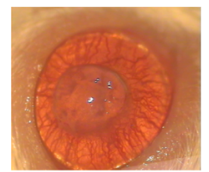

Day 15

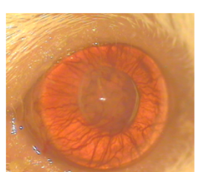

Day 20

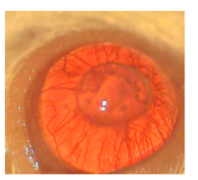

Day 21
Allogeneic

Transplantation

Allogeneic

Transplantation +

$5 \times 10^{4}$ allo MSC

Fig. 1 Subconjunctival administration of allogeneic MSCs prolongs corneal allograft survival. Female Balb/c mice served as recipients for female C57BL/6 donor corneas. Different doses of allogeneic (donor-derived) MSCs were injected subconjunctivally 7 days before transplantation (D-7). Mice were observed every 2/3 days. a Kaplan-Meier survival curve analysis of allogeneic transplant controls (black line) $(n=9)$, corneal allograft + $5 \times 10^{5}$ MSCs (pink line) $(n=6)$, and corneal allograft $+5 \times 10^{4}$ MSCs (green line) $(n=4)$ (Log-rank (Mantel-Cox) test, $\left.{ }^{* *} p \leq 0.01,{ }^{* * *} p \leq 0.001\right) . \mathbf{b}$ Opacity and c neovascularization scores up to POD 40. d Representative light microscopy images of corneal allografts taken at two posttransplantation time points from two separate mice either treated with low-dose allo-MSCs or untreated. $n=4-6$ with numbers per treatment group the same as in $\mathbf{a}$. Error bars show mean $+\mathrm{SD}$

\section{Discussion}

The field of MSC therapies has grown exponentially over the last decade with MSCs being applied in many disease settings but with mixed beneficial results $[4,13]$. Many important issues for the success of clinical applications of MSCs such as timing of cell administration, dose, and origin of MSCs are still not solved satisfactorily, therefore warranting further in vitro and pre-clinical investigations. Here we show that local, subconjunctival injection of allogeneic MSCs is as efficient as intravenous injection in modulating corneal allograft survival $[7,19]$ but at very low doses $\left(5 \times 10^{4} \mathrm{MSCs}\right)$. This is significant as this novel low-dose injection protocol may also reduce the risk of potential side effects of allogeneic cell administration in patients. Moreover, it will allow a much larger number of patients to be treated per donor bone marrow, thereby contributing to reducing the costs of cell manufacturing for clinical trials. Interestingly, both tested subconjunctival injection strategies using different time points (day -7 or day - 

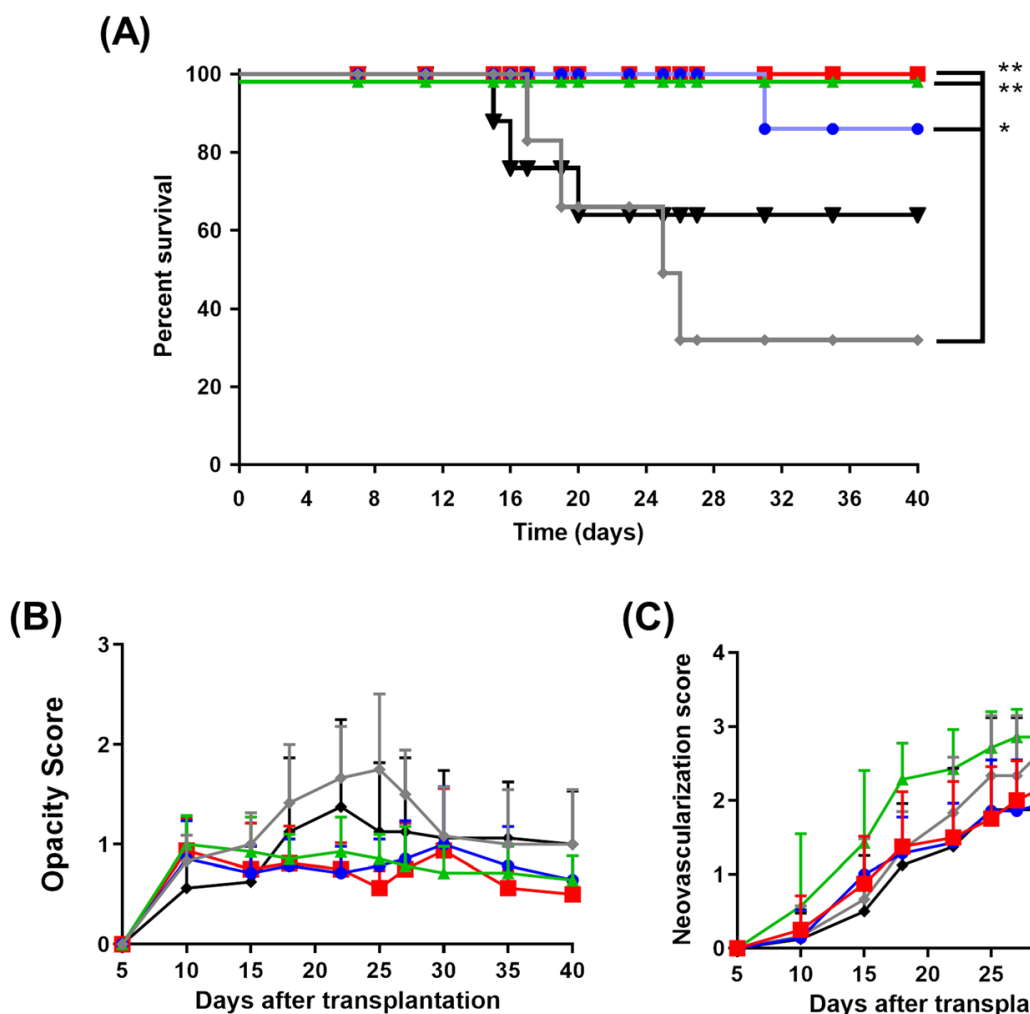

(C)

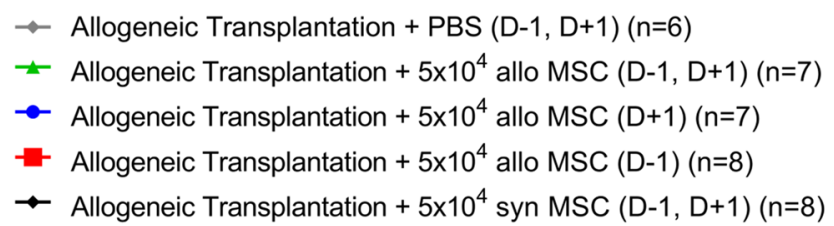

Fig. 2 Subconjunctival administration of low-dose allogeneic MSCs prolongs corneal allograft survival with pre-transplant injection the crucial factor. Female Balb/c mice served as recipients for female C57BL/6 donor corneas. Allogeneic MSCs were administered subconjunctivally using three different treatment strategies. Mice received one injection of $5 \times 10^{4} \mathrm{MSC}$ s either the day before transplantation (D-1) or the day after transplantation $(D+1)$ or two separate doses at $D-1$ and $D+1$. Control mice received PBS alone at $D-1$ and $D+1$. Mice were observed every $2 / 3$ days. a Kaplan-Meier survival curve analysis of corneal allograft + PBS $(D-1, D+1)$-treated control mice (gray line) $(n=6)$, corneal allograft $+5 \times 10^{4}$ allogeneic MSCs $(D-1, D+1)$ (green line) $(n=7)$, corneal allograft $+5 \times 10^{4}$ allogeneic MSCs $(D+1)$ (blue line) $(n=7)$, corneal allograft $+5 \times 10^{4}$ allogeneic MSCs (D-1) (red line) $(n=8)$, and corneal allograft $+5 \times 10^{4}$ syngeneic MSCs ( $\left.-1, D+1\right)$ (black line) $(n=8)$ (Log-rank (Mantel-Cox) test, $\left.{ }^{*} p \leq 0.05,{ }^{* *} p \leq 0.01\right)$. b Opacity and $\mathbf{c}$ neovascularization scores up to POD $40 . n=6-8$ with numbers per treatment group the same as in $\mathbf{a}$. Error bars show mean $+S D$

$1 /+1$ ) resulted in equally efficient prevention of corneal transplant rejection, indicating that the time point of cell administration is less important in this disease setting. Of note, double injection of syngeneic/autologous (recipient-derived) MSCs did not lead to significant prolongation of allograft survival, a phenomenon which we have previously described $[7,10]$. Immunomodulatory effects following intravenous infusion of MSCs can be regulated through the myeloid cell-mediated induction of Foxp $3^{+}$regulatory $\mathrm{T}$ cells in the lung, a phenomenon which was first described by Ko et al. [11] and confirmed by us and others $[9,10,20,21]$. Interestingly, the injection of $5 \times 10^{4}$ MSCs in the subconjunctival space is unlikely to result in these MSCs migrating to the lung to exert their therapeutic effect; therefore, other mechanisms of MSC immunomodulation are likely at play. It is likely that MSCs not only have the capacity to modulate monocytes/macrophages in the lung but also in other immunorelevant compartments such as in the eye, the conjunctiva-associated lymphoid tissues (CALT), or in the draining lymph nodes. Indeed, we found that subconjunctival injection of MSCs leads to detectable 

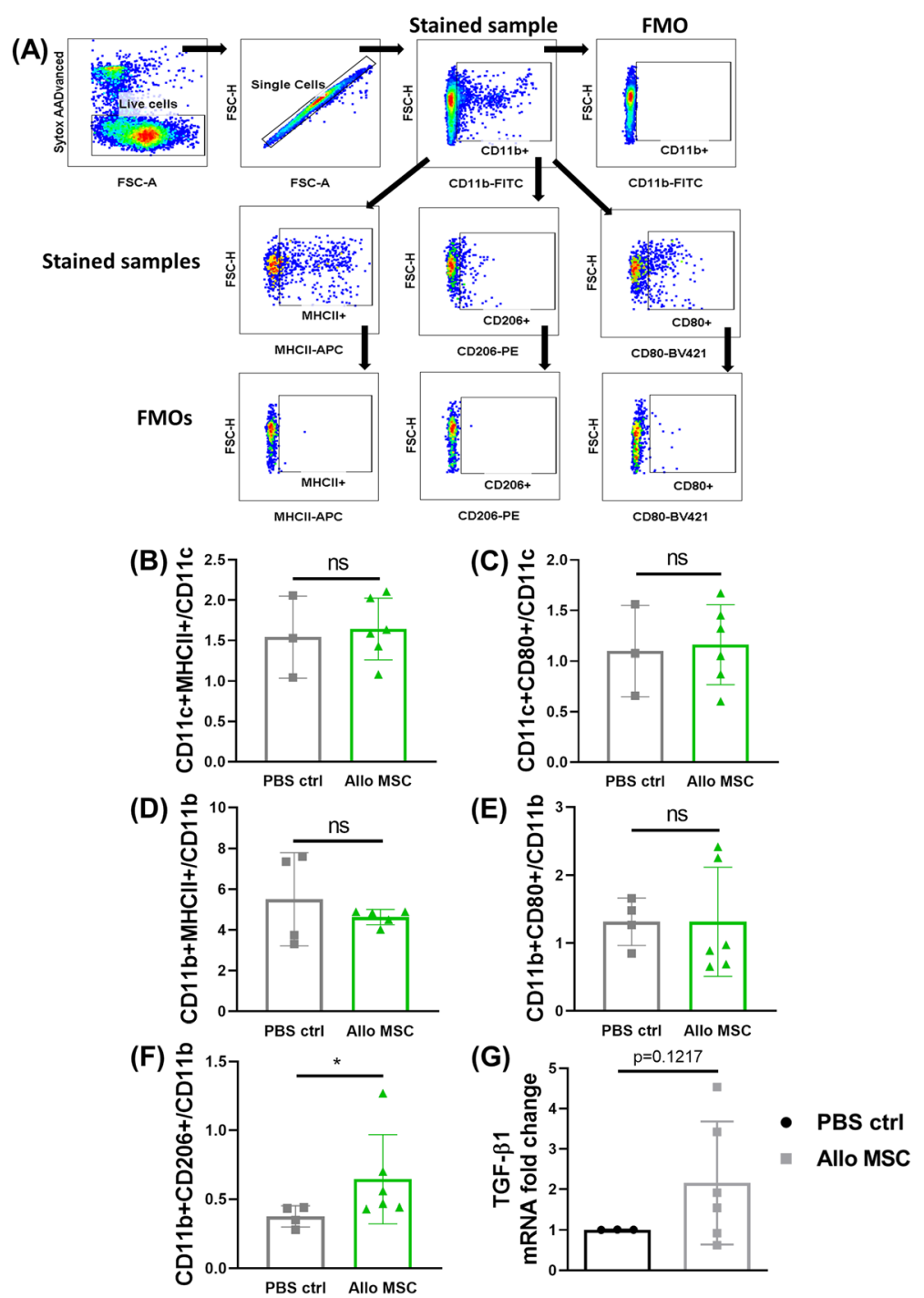

Fig. 3 Dual administration of low-dose allogeneic MSCs induces a higher proportion of anti-inflammatory mononuclear phagocytes in the draining lymph nodes. Draining lymph nodes (dLNs) were harvested 2 days post-transplantation $(D+2)$ from corneal allograft recipient mice receiving either two injections of PBS or low-dose allogeneic MSCs the day before transplantation (D-1) and the day after transplantation (D+1). a Flow cytometry gating strategy used to select activated dendritic cells (DCs) (CD11c+MHCII+, CD11c+CD80+) or mononuclear phagocytes (MPh) with either a pro-inflammatory (CD11b+MHCll+, CD11b+CD80+) or an anti-inflammatory (CD11b+CD206+) phenotype. b Proportion of $\mathrm{MHCl}+\mathrm{DC}$ expressed as a percentage of the parent $(\mathrm{CD} 11 \mathrm{C}+)$ population. $\mathbf{c}$ Proportion of $\mathrm{CD} 80+\mathrm{DCs}$ expressed as a percentage of the parent $(\mathrm{CD} 11 \mathrm{c}+)$ population. $\mathbf{d}$ Proportion of $\mathrm{MHCll}+\mathrm{MPh}$ expressed as a percentage of the parent (CD11b+) population. e Proportion of CD80+ MPh expressed as a percentage of the parent $(C D 11 b+)$ population. $\mathbf{f}$ Proportion of $C D 206+$ MPh expressed as a percentage of the parent $(C D 11 b+)$ population. $\mathbf{g}$ Analysis of mRNA expression (normalized to the housekeeping gene GAPDH and shown as fold-change relative to the PBS-treated allogeneic control group) in the dLNs of TGF- $\beta 1$ at D+2 from PBS-treated allogeneic controls and low-dose allogeneic MSC-treated corneal allograft recipients. Error bars: mean \pm SD. ${ }^{*} p<0.05$ (each individual dot represents a separate animal, $n=3-6$ ). D'Agostino and Pearson omnibus normality test and Shapiro-Wilk normality test used to determine the distribution of data. ROUT testing was used to identify outliers. Nonparametric unpaired two-tailed Student's $t$ tests used for data that was not normally distributed

changes in the expression profile of innate immune cells in the draining lymph nodes as early as 2 days after transplantation, resulting in a significant upregulation of CD206 expression on mononuclear phagocytes. This suggests that 1-3 days after MSC administration, a skewing of the anti-graft immune response towards a more anti-inflammatory or wound healing phenotype has occurred.

In conclusion, we have shown that the subconjunctival administration of MSCs has the potential to significantly prolong corneal allograft survival using a single injection strategy and a much reduced MSC dose compared to 


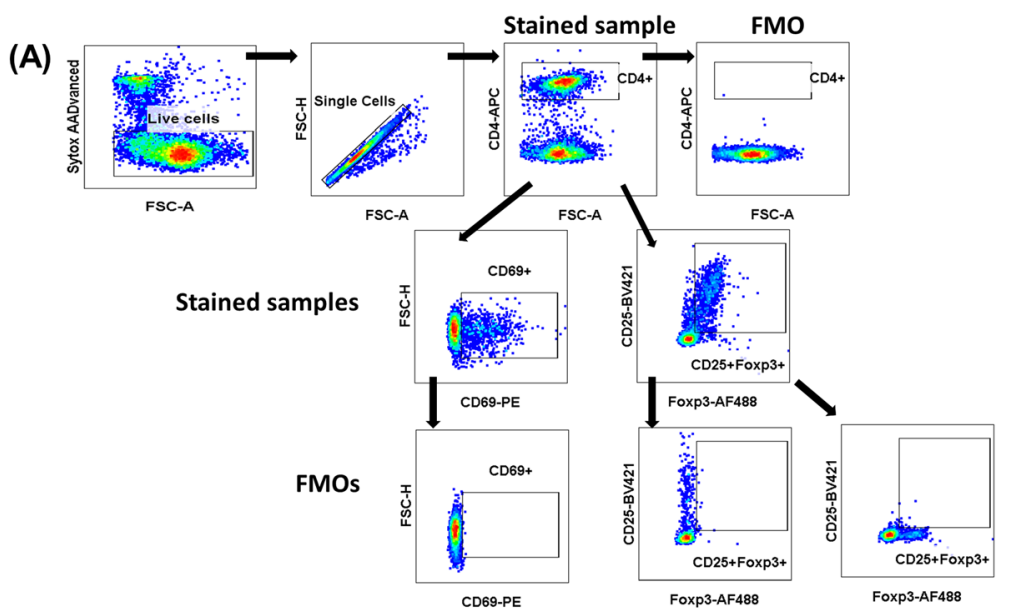

(B)

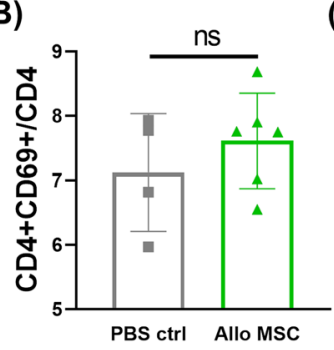

(C)

(D)
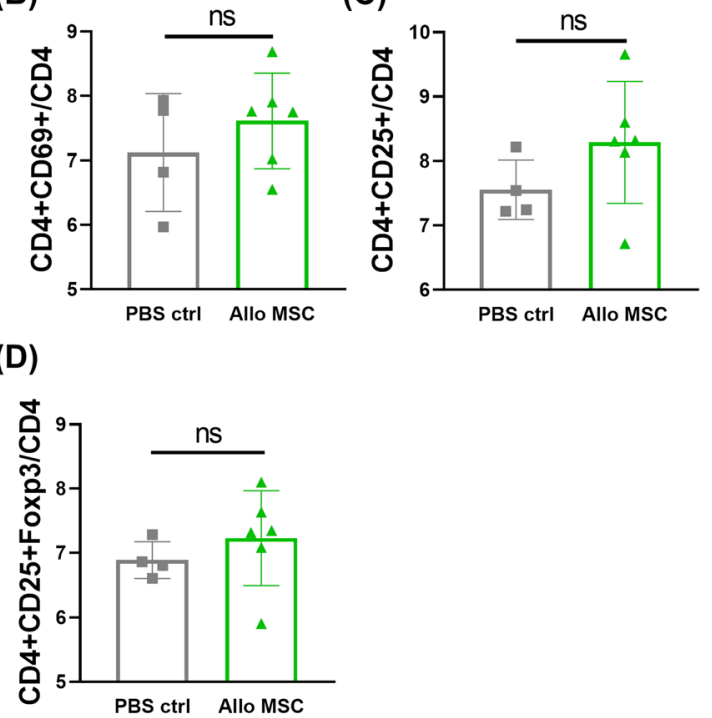

Fig. 4 Dual administration of low-dose allogeneic MSCs does not significantly alter the frequency of activated CD4+ T cells or regulatory T cells in the draining lymph nodes. Draining lymph nodes (dLNs) were harvested at D+2 from corneal allograft recipient mice receiving either two injections of PBS or low-dose allogeneic MSCs ( $D-1$ and $D+1)$. a Flow cytometry gating strategy used to select activated CD4+ T cells (CD4+CD25+ or CD4+CD69+) or regulatory T cells (Tregs) (CD4+CD25+Foxp3+). b Proportion of CD69+ T cells expressed as a percentage of the parent (CD4+) population. $\mathbf{c}$ Proportion of CD25+ T cells expressed as a percentage of the parent (CD4+) population. $\mathbf{d}$ Proportion of CD25+Foxp3+ Tregs expressed as a percentage of the parent (CD4+) population. Error bars: mean \pm SD (each individual dot represents a separate animal, $n=4-6)$. D'Agostino and Pearson omnibus normality test and Shapiro-Wilk normality test used to determine distribution of data. ROUT testing was used to identify outliers. Non-parametric unpaired two-tailed Student's $t$ tests used for data that was not normally distributed

systemic administration. This novel injection protocol could lead to the development of novel therapeutic treatment regimens for patients who suffer from adverse immune reactions towards an allogeneic corneal transplant and with much reduced cell numbers enhancing safety and efficacy of cellular therapies.

\section{Abbreviations}

MSCs: Mesenchymal stromal cells; Tregs: Regulatory T cells; MHC: Major histocompatibility complex; DPBS: Dulbecco's phosphate-buffered saline; dLNs: Draining lymph nodes; ISCT: International Society for Cell Therapy; MST: Mean survival time; Arg-1: Arginase-1; CALT: Conjunctiva-associated lymphoid tissues; POD: Post-operation day; MPh: Mononuclear phagocytes; DCs: Dendritic cells

\section{Supplementary Information}

The online version contains supplementary material available at https://doi. org/10.1186/s13287-021-02293-X.

Additional file 1: Table S1. Antibodies used for flow cytometry.

Additional file 2: Supplemental Figure 1. Surface profile characterization of C57BL/6 MSCS.

Additional file 3: Supplemental Figure 2. Osteogenic and adipogenic differentiation of C57BL/6 MSCs.

Additional file 4: Supplemental Figure 3. Dual administration of lowdose allogeneic MSCs does not significantly alter the frequency of mononuclear phagocytes or activated dendritic cells in the spleen. 
Additional file 5: Supplemental Figure 4. C57BL/6 MSCs polarize M0 and skew M1-like macrophages towards an-anti-inflammatory, M2-like phenotype after co-culture.

\section{Acknowledgements}

All flow cytometry experiments were performed in the NUI Galway Flow Cytometry Core Facility, which is supported by funds from NUI Galway, Science Foundation Ireland, the Irish Government's Programme for Research in Third Level Institutions, Cycle 5, and the European Regional Development Fund. The authors wish to thank the Bio-Resources Unit technical, veterinary, and administrative staff in NUI Galway for facilitating in vivo studies and for their ongoing assistance, advice, and support in animal models of disease husbandry, care, and welfare. The authors would like to thank Dr. Karen English, Maynooth University, Ireland, for providing C57BL/6 MSCs used in some in vitro experiments.

\section{Authors' contributions}

Substantial contributions to the conception or design of the work (O.T., K.L., N.M., G.F., A.E.R., T.R.); or the acquisition (O.T., K.L., N.M., X.C., E.D., A.C., P.L., A.E.R., T.R.), analysis (O.T., K.L., N.M., X.C., E.D., A.C., P.L., A.E.R., T.R.), or interpretation of data for the work (O.T., K.L., N.M., X.C., E.D., A.C., P.L., G.S., A.E.R., T.R.); AND Drafting the work or revising it critically for important intellectual content (O.T., K.L., N.M., X.C., E.D., A.C., P.L., G.S., G.F., A.E.R., T.R.); AND Final approval of the version to be published (O.T., K.L., N.M., X.C., E.D., A.C., P.L., G.S., G.F., A.E.R., T.R.); AND Agreement to be accountable for all aspects of the work in ensuring that questions related to the accuracy or integrity of any part of the work are appropriately investigated and resolved (O.T., K.L., N.M., X.C., E.D., A.C., P.L., G.S., G.F., A.E.R., T.R.).

\section{Funding}

This study was supported by a Science Foundation Ireland Investigator Award (Grant 12/IA/1624; T.R.), a Science Foundation Ireland Starting Investigator grant (15/SIRG/3456; A.E.R.) and Frontiers for the Future Program (19/FFP/6446; A.E.R.), and the European Regional Development Fund. This project has also received funding from the European Union's Horizon 2020 research and innovation program under grant agreement no. 814439. E.D. is funded by a Government of Ireland Postgraduate Scholarship (GOIPG/2018/ 1887) and supported by funding from the College of Medicine, Nursing and Health Sciences, National University of Ireland Galway.

\section{Availability of data and materials}

The datasets used and/or analyzed during the current study are available from the corresponding author on reasonable request.

\section{Declarations}

\section{Ethics approval and consent to participate}

All procedures performed on mice were approved by the Animals Care Research Ethics Committee of the National University of Ireland, Galway (NUIG), and conducted under individual and project authorization licenses from the Health Products Regulatory Authority (HPRA) of Ireland. All animals were housed and cared for under Standard Operating Procedures of the Animal Facility at the Biomedical Sciences Biological Resource Unit, NUIG.

\section{Consent for publication}

Not applicable.

\section{Competing interests}

The authors declare that they have no competing interests.

\section{Author details}

'College of Medicine, Nursing and Health Sciences, Biomedical Sciences, Regenerative Medicine Institute, National University of Ireland Galway, Galway, Ireland. ${ }^{2}$ Discipline of Pharmacology and Therapeutics, College of Medicine, Nursing and Health Sciences, National University of Ireland Galway, Galway, Ireland. ${ }^{3}$ Department of Ophthalmology, University Hospital Galway, National University of Ireland Galway, Galway, Ireland. ${ }^{4}$ CURAM Centre for Research in Medical Devices, National University of Ireland, Galway, Ireland.
Received: 20 January 2021 Accepted: 17 March 2021

Published online: 06 April 2021

\section{References}

1. George AJ, Larkin DF. Corneal transplantation: the forgotten graft. Am J Transplant Off J Am Soc Transplant Am Soc Transplant Surg. 2004;4(5):67885. https://doi.org/10.1111/j.1600-6143.2004.00417.x.

2. Pleyer U, Schlickeiser $\mathrm{S}$. The taming of the shrew? The immunology of corneal transplantation. Acta Ophthalmol. 2009:87(5):488-97. https://doi. org/10.1111/j.1755-3768.2009.01596.x

3. Armitage WJ, Goodchild C, Griffin MD, Gunn DJ, Hiortdal J, Lohan P, Murphy CC, Pleyer U, Ritter T, Tole DM, Vabres B. High-risk corneal transplantation: recent developments and future possibilities. Transplantation. 2019:103(12): 2468-78. https://doi.org/10.1097/TP.0000000000002938.

4. Griffin MD, Elliman SJ, Cahill E, English K, Ceredig R, Ritter T. Concise review: adult mesenchymal stromal cell therapy for inflammatory diseases: how well are we joining the dots? Stem Cells. 2013;31(10):2033-41. https://doi. org/10.1002/stem.1452.

5. Murphy N, Lynch K, Lohan P, Treacy O, Ritter T. Mesenchymal stem cell therapy to promote corneal allograft survival: current status and pathway to clinical translation. Curr Opin Organ Transplant. 2016;21(6):559-67. https:// doi.org/10.1097/MOT.0000000000000360.

6. Oh JY, Lee RH, Yu JM, Ko JH, Lee HJ, Ko AY, Roddy GW, Prockop DJ Intravenous mesenchymal stem cells prevented rejection of allogeneic corneal transplants by aborting the early inflammatory response. Mol Ther 2012:20(11):2143-52. https://doi.org/10.1038/mt.2012.165.

7. Treacy O, O'Flynn L, Ryan AE, Morcos M, Lohan P, Schu S, Wilk M, Fahy G, Griffin MD, Nosov M, Ritter T. Mesenchymal stem cell therapy promotes corneal allograft survival in rats by local and systemic immunomodulation. Am J Transplant Off J Am Soc Transplant Am Soc Transplant Surg. 2014; 14(9):2023-36. https://doi.org/10.1111/ajt.12828.

8. Omoto M, Katikireddy KR, Rezazadeh A, Dohlman TH, Chauhan SK. Mesenchymal stem cells home to inflamed ocular surface and suppress allosensitization in corneal transplantation. Invest Ophthalmol Vis Sci. 2014; 55(10):6631-8. https://doi.org/10.1167/iovs.14-15413.

9. Murphy N, Treacy O, Lynch K, Morcos M, Lohan P, Howard L, Fahy G, Griffin $M D$, Ryan AE, Ritter T. TNF-alpha/L-1 beta-licensed mesenchymal stromal cells promote corneal allograft survival via myeloid cell-mediated induction of Foxp3(+) regulatory T cells in the lung. FASEB J. 2019;33(8):9404-21. https://doi.org/10.1096/fj.201900047R.

10. Lynch K, Treacy O, Chen X, Murphy N, Lohan P, Islam MN, Donohoe E, Griffin MD, Watson L, McLoughlin S, O'Malley G, Ryan AE, Ritter T. TGFbeta1-licensed murine MSCs show superior therapeutic efficacy in modulating corneal allograft immune rejection in vivo. Mol Ther. 2020;28(9): 2023-43. https://doi.org/10.1016/j.ymthe.2020.05.023.

11. Ko JH, Lee HJ, Jeong HJ, Kim MK, Wee WR, Yoon SO, Choi H, Prockop DJ, Oh JY. Mesenchymal stem/stromal cells precondition lung monocytes/ macrophages to produce tolerance against allo- and autoimmunity in the eye. Proc Natl Acad Sci U S A. 2016;113(1):158-63. https://doi.org/10.1073/ pnas.1522905113.

12. Moll G, Rasmusson-Duprez I, von Bahr L, Connolly-Andersen AM, Elgue $G$, Funke L, Hamad OA, Lönnies H, Magnusson PU, Sanchez J, Teramura Y, Nilsson-Ekdahl K, Ringdén O, Korsgren O, Nilsson B, le Blanc K. Are therapeutic human mesenchymal stromal cells compatible with human blood? Stem Cells. 2012:30(7):1565-74. https://doi.org/10.1002/stem.1111.

13. Rendra E, Scaccia E, Bieback K. Recent advances in understanding mesenchymal stromal cells. F1000Res. 2020;9:F1000 Faculty Rev-156. https:// doi.org/10.12688/f1000research.21862.1.

14. Yao L, Li ZR, Su WR, Li YP, Lin ML, Zhang WX, Liu Y, Wan Q, Liang D. Role of mesenchymal stem cells on cornea wound healing induced by acute alkali burn. Plos One. 2012;7(2):e30842. https://doi.org/10.1371/journal.pone.003 0842.

15. Shukla S, Mittal SK, Foulsham W, Elbasiony E, Singhania D, Sahu SK, Chauhan SK. Therapeutic efficacy of different routes of mesenchymal stem cell administration in corneal injury. Ocular Surface. 2019;17(4):729-36. https://doi.org/10.1016/j.jtos.2019.07.005.

16. Jia Z, Li F, Zeng X, Lv Y, Zhao S. The effects of local administration of mesenchymal stem cells on rat corneal allograft rejection. BMC Ophthalmol. 2018;18(1):139. https://doi.org/10.1186/s1 2886-018-0802-6.

17. Duffy MM, Pindjakova J, Hanley SA, McCarthy C, Weidhofer GA, Sweeney EM, English K, Shaw G, Murphy JM, Barry FP, Mahon BP, Belton O, Ceredig R, 
Griffin MD. Mesenchymal stem cell inhibition of T-helper 17 celldifferentiation is triggered by cell-cell contact and mediated by prostaglandin E2 via the EP4 receptor. Eur J Immunol. 2011;41(10):2840-51. https://doi.org/10.1002/eji.201141499.

18. Schu S, Nosov M, O'Flynn L, Shaw G, Treacy O, Barry F, Murphy M, O'Brien T, Ritter T. Immunogenicity of allogeneic mesenchymal stem cells. J Cell Mol Med. 2012;16(9):2094-103. https://doi.org/10.1111/j.1582-4934.2011.01509.x

19. Lohan P, Murphy N, Treacy O, Lynch K, Morcos M, Chen B, Ryan AE, Griffin $M D$, Ritter T. Third-party allogeneic mesenchymal stromal cells prevent rejection in a pre-sensitized high-risk model of corneal transplantation. Front Immunol. 2018;9:2666. https://doi.org/10.3389/fimmu.2018.02666.

20. Lohan P, Treacy O, Morcos M, Donohoe E, O'Donoghue Y, Ryan AE, et al. Interspecies incompatibilities limit the immunomodulatory effect of human mesenchymal stromal cells in the rat. Stem Cells. 2018;36(8):1210-5. https:// doi.org/10.1002/stem.2840.

21. Lee HJ, Ko JH, Kim HJ, Jeong HJ, Oh JY. Mesenchymal stromal cells induce distinct myeloid-derived suppressor cells in inflammation. JCI Insight. 2020; 5(12):e136059. https://doi.org/10.1172/jci.insight.136059.

\section{Publisher's Note}

Springer Nature remains neutral with regard to jurisdictional claims in published maps and institutional affiliations.

Ready to submit your research? Choose BMC and benefit from:

- fast, convenient online submission

- thorough peer review by experienced researchers in your field

- rapid publication on acceptance

- support for research data, including large and complex data types

- gold Open Access which fosters wider collaboration and increased citations

- maximum visibility for your research: over $100 \mathrm{M}$ website views per year

At $B M C$, research is always in progress.

Learn more biomedcentral.com/submissions 